when considering the theory of fever. This increased body heat is, it will be seen, only one of a group of phenomena, each of which is the direct or indirect result of the propagation of the contagium in the tissues. The direct action of the contagium consists in the consumption by it of the nitrogen and water of the constructive store albumen. The results of this action are: 1 . Impoverishment, and consequent wasting of the nitrogenous tissues. 2. Increased demand for water, with its attendant thirst, dry skin, scanty urine, and constipated bowels. 3. Increased tissue metabolism, with its attendant increased rapidity of the circulation increased formation of urea, and increased production of heat. Thus we find that the phenomena which must result from the propagation of an organism in the tissues ar exactly those which are found to characterise the febrile state. Thus is explained the mode of action of the poisons of the specific fevers. Thus, too, is exemplified the combustion theory of fever.

Let me again point out that the two theories of fever which we have been considering are not antagonistic Each has its own special sphere of application. The chief and most important applications of the neurotic thecry have already been indicated. It applies probably to all cases of hyperpyrexia, to all rises of temperature resulting from non-inflammatory lesions of the nervous centres, and probably, too, to most forms of ephemeral fever. By the combustion theory are to be explained the febrile symptoms of the specific fevers, malarial fevers, rheumatic fever, pneumonia, and all febrile diseases, whose poisons may reasonably be regarded as minute organisms whose morbific action is dependent on their organic development. It is probable, too, that the fever of all inflammations is also thus produced. Not that all inflammations are produced by foreign organisms (though many probably are), but because excessive activity in the pinute cellular elements of the tissues will have the same result on their metabolism as the propagation in them of foreign organisms.

Cadogan-place, S.W

\section{ON THE ACTION AND PROPERTIES OF THE} WHITE BLOOD-CELLS.

DO THE INTRA-VASCULAR WHITE BLOOD-CELLS POSSESS THE PROPERTY OF AMGEBOID CHANGE OF SHAPE AND POSITION? IS THE ASSEVERATED MIIGRATION OF WHITE BLOOD-CELLS AN OBSERVABLE PHENOMENON OF INFLAMIMATION?

BY WM. A. HAMAN, M.D.

IN the American reprint of THE LANCET for the month of March, 1885, Mr. Wharton Jones has an interesting paper addressed to professors of physiology and patbology, advising them not to teach that white cells migrate from the veins and capillaries during inflammation until they have verified the fact by observations of their own. In this paper Mr. Jones makes two unqualified assertions which negatively answer the questions which constitute the caption of this communication. Prior to the appearance of Mr. Jones's paper I had unreservedly accepted the doctrine of migration as beyond dispute, but after reading the convictions of one of the pioneers in the microscopical study of the circulation and inflammation, I thought I would repeat some of these experiments for my own satisfaction. I accordingly made twenty prolonged observations on the transparent membranal web, mesentery, and tongue of toads and frogs, using Schäfer's work on "Practical Histology" as a guide to the systematic display of these parts.

Concerning the first question, I would remark that, although Dr. Henry Green says "amcboid movements have never been seen in the white corpuscles whilst within the vessels," agreeing in this respect with Mr. Jones, while a firm believer in Cohnheim's views regrarding migration, $1 \mathrm{gm}$ convinced that both are in error. I have demonstrated the contrary to my own satisfaction at least. During last September I had a small vein in the mesentery of a frog under a $\frac{1}{6}$-inch objective (using a cover-glass); there were white globules hugging the vessel wall, while the axis of the contents of the vessel oscillated gently to and fro; the walls of the vessel were sharply outlined, the surrounding tissue

1 Pathology and Morbid Anatomy, sixth edition, p. 216. being nearly free from stray globules, and the colourless corpuscles were well defined. I carefully and closely watched one white globule in the centre of the tube; it was motionless, but gradually changed its shape by throwing out processes, and finally by imuerceptible activity reached one side of the vessel, and there changed from the circular shape to that of a somewhat irregular square. I thought I was now going to witness migration; but in a short time it left the side of the vessel, resumed its circular shape, and returned to the centre of the vessel, where it let go its hold on the vessel wall and oscillated to and fro with the current in company with the other red and white globules-thus showing it to be still within the vessel. I believe, notwithstanding the assertions of Mr. Jones and Dr. Green to the contrary, that it was a bonâ-fide instance of amœboid change of shape and position of a white corpuscle while still within a vessel. Using the same objective, I afterwards observed the same phenomenon in the case of other colourless cells. On account of the inconveniently short working distance of the $\frac{1}{6}$-inch objective, the $\frac{1}{4}$-inch is generally used, which, possessing a less power of amplification, may account for the failure to witness this change of shape and position; by having the membrane perfectly horizontal, and using very short pins to confine the membrane to the frogplate, I experienced no great difficulty; a $\frac{1}{4}$-inch glass used in conjunction with an achromatic amplifier would give the same amplification as a $\frac{1}{8}$-inch objective without the inconvenience of a short working distance.

In reference to the second question, I would say that if I was at all prejudiced it was in favour of the migration theory; for, if correct, it very much simplifies the pathology of inflammation. I used the web but once, as on account of its comparative thickness and the numerous pigment cells contained in it its examination was not so satisfactory as the clear transparent mesentery. In some instances I relied on atmospheric air to light up the inflammatory process; while in others $I$ appled acetic acid, crystals of silver nitrate and copper sulphate, and an iron heated short of red heat and in boiling water. With the exception of the web, I invariably noticed, at the first glance at the exposed membranes, that there were free cells on their surfaces. These are the white cells not only coming, as Mr. Jones observes, from the peritoneal secretion, but also from the vessels, as red cells are also to be found. Many of these cells, without doubt, come from the vessels divided in opening the abdomen, and from the pricks of the pins made in confining the mesentery; small vessels must also be severed in properly displaying the tongue. No matter how much care is taken in the preparation of these membranes, free cells will always be found on their surfaces, and no doubt are mistaken by some to be migrated globules; but a very little care in observing them will readily dispel such an illusion. Furthermore, I always noticed that the great majority of them can be removed by means of a camelhair brush; those which do not come away are no doubt on the under surface of the membrane, where manipulation with the brush is difficult and awkward, or else, being bodies of microscopic size, escape being entangled in the hair of the brush. My plan was to select a few small veins with a clear unobstructed piece of membrane on each side of the vessels, and then watch until the current became slow and finally stagnant, with complete coagulation of their contents. I never saw, no matter how long the vessels were under observation, any white cells appear in the surrounding clear tissue which could not be accounted for on another more plausible theory than that of migration. Vessels were occasionally seen the tissues bordering which were not free from leucocytes, and which could not be brushed away. I do not believe they were migrated globules, for they did not change their position, and if the membrane was occasionally brushed they did not increase in number. I believe they were free peritoneal and vascular cells fixed to the membrane by their viscidity and desiccation prior to inflammatory effusion. I several times saw a small vein, sharply defined and with clear tissue surrounding it, in which a colourless cell was to be seen that presented the appearance as though a small portion of it were partly through the vessel wall; but after long waiting, during which time it presented no change of any kind, it was suddenly whisked along with the blood-current. I repeatedly proved, to my own satisfaction, by transitional focusing, that many of the cells that occupied positions which rendered them liable to be mistaken for migrating leucocytes were on a plane different from that occupied by the vessel. The most deceptive 
simulation of migration I witnessed was observed while watching two leucocytes which looked for all the world like globules that had partly escaped from the vessel. As they were the only ones, and the surrounding tissue was quite clear and free from other globules, I was less liable to make a mistake than would otherwise have been the case. They appeared to be attached to the wall of the vessel by a narrow pedicle, which gave them a pear-shape. In about an hour they were quite free from the vessel, and had moved a short distance away from it; but in a comparatively short time they returned to the vessel wall again, and appeared to almost bury themselves in it, when they reappeared, still apparently attached to the vessel wall. This peculiar behaviour made me doubt their being emigrant globules, but I was finally convinced, by their suddenly rapidly oscillating, in no fixed direction, to and fro in overlying serum on the peritoneal (the vessel was in the mesentery) surface, so occasioned by the beating of a neighbouring large artery. This proved their presence on the surface of the mesentery, wandering over its surface, and thus occasioning the similarity in appearance to migration. This required an hour and a half of continuous observation; so a hasty conclusion in favour of migration would no doubt have been arrived at by many.

On reading descriptions of the migratory process by different writers one is struck with two facts: (1) That exceedingly few quote their own observations in favour of migration, but quote either Cohnheim's or those of Burdon Sanderson; (2) the great discrepancy in the ease with which they (different writers) say migration can be observed. Burdon Sinderson avers, "From the description given above it might be inferred that the experiment is one of great simplicity, whereas in actus practice it is attended with very considerable difficulty; so much so, indeed, that most persons who have tried it have found failure more frequent than success. The principal sources of difficulty are: (1) That the time occupied in the first stage of the process, during which the circulation is going on with unabated velocity, is extremely variable; (2) that if from weariness or inadvertence the attention of the observer is diverted from the selected vein at the commencement of the pro ess of migration, he is very unlikely to succeed in seeing what he desires to see afterwards; for inasmuch as leucocytes are escaping simultaneously in various parts of the mesentery, they soon accumulate in such numbers that their mode of exit can no longer be distinguished. Yet, notwithstanding these difficulties, no one who has time and patience enough nesd fail ; great care in manipulation is required, but no extraordinary dexterity." " (A camel-hair brush, as before stated, occasionally applied to the surface of the membrane will prevent and will remove the obstruction to the clearness of view occasioned by these "accumulated migrated" corpuscles which gradually ooze from the cut vessels). I now turn to Schäfer, who, speaking of the exposed lymphatic surface of the tongue, says: "Moreover, the mere exposure of the lymphatic surface soon causes inflammatory changes, and after the preparation has been made a $f_{\theta} w$ minutes only, the first commencement of these is seen in the sticking of the pale corpuscles to the walls of the vessels, speedily followed by their migration from the veins into the surrounding tissue. Nowhere can the fact be more clearly established, and the details of the process more accurately followed than here." ${ }^{3}$ If migration is an observable fact, on $\theta$ of these gentlemen is in error, and I am sure it is Mr. Schäfer, who, I have not the least doubt, mistakes the free leucocytes on the surface for migrated corpuscles in the parenchyma of the tissues. My observations have been too few to warrant me in coming to a definite conclusion; yet the result of my efforts to arrive at the truth in conjunction with the differences in the statements of actual observers who accept the doctrine of migration give some support to the assertion of Mr. Wharton Jones. I intend pursuing the subject still further, and if after as many careful observations I do not witness migration, I think I shall be justified in doubting, if not migration, at least observable migration.

Reading, Pennsylvania.

2 Holmes' System of Surgery, vol. i., p. 48 . Practical Histology, p. 161.

The epidemic of messles has rapidly spread in Warrington during the past two or tbree weeks, and the day-schools in the town have been closed with a view to prevent the spread of infection.

\section{HYSTERECTOMY FOR FIBRO-MYOMA UTERI IN A PATIEN'T FIFTY-SIX YEARS OF AGE.}

By J. KNOWSLEY THORNTON, M.B., C.M., SURGEON TO THE SAMARITAN FREE HOSPITAL.

The following case seems to me sufficiently rare to merit separate publication.

On Nov. 3rd, 1886, I saw in consultation with Dr. Braxton Hicks and Mr. Rand of Dulwich a single lady, aged fiftysix, with a very large, solid abdominal tumour. After examination, I agreed with the previous diagnosis-namely, that it was uterine. The cervix was obliterated, and the os could only just be reached as a small opening at the top of an elongated funnel-shaped vagina. Menstruation had been regular and scanty up to 1880 , and then became rather more profuse. In July, 1881, the patient discovered a small lump in her right side, and about the same time menstruation became irregular, and she had some severe floodings. This state of things continued more or less till the early part of 1885 , the tumour meantime slo wly increasing in size. She then stopped menstruating for a whole year, had one period, and did not menstruate again for another six months--i.e., till I first saw her. During this last six month increase in size had been much more rapid and decline of general health so marked that Dr. Hicks advised that I should be consulted as to the possibility of operation. I came to the conclusion that hysterectomy was possible and justifiable, but thought it right to tell both the patient and ber friends that the great $s^{2} z e$ of the tumour, together with its very broad base, made the operation unusually formidable and dangerous. I have twice performed hysterectomy upon single women at the age of fifty-five, in the one case removing an enormous fibro-myoma, which had become cystic with rapid increase of size, and in the other a small fibro-myoma for excessive hæmorrhage, which rather increased than diminished after the usual period for the menopause; and in another case I operated on a woman of fifty-eight, in consequence of profuse suppuration in the tumour, the pus escaping through the uterus in such quantity as to seriously undermine her health. These three patients are now all in the enjoyment of good health.

The special interest in the present case does not therefore lie in the age of the patient, but in the fact that the tumour appeared first about the usual time of change of life, and grew steadily during this period, and after it was practically complete increased so rapidly in size as to threaten the patient's life. Her family history is a remarkable one. She was the eighth of a family of sixteen. Her mother died of some uterine disease at sixty-four, one sister died in infancy, one of phthisis at nineteen, another of epilepsy, and another of scarlet fever. The eldest sister had a tumour removed from her groin ten years ago, another sister had a mammary tumour removed four years ago, and the youngest sister has been twice operated upon for thyroid tumour; all three are living.

On Nov. 8th, 1886, Mr. Stormont Murray administering chloroform, Mr. Malcolm assisting, and Dr. Braxton Hicks and Mr. Rand being present, I removed the tumour with the uterus down to the internal os and both ovaries and tubes. The latter were ligatured off, and the wire of Koeberle's serre-nœud was passed through the broad ligament on each side just below the cut angle made by removing the appendages. It was necessary not only to secure the broad ligaments on each side as in ovariotomy, but also to secure separately on each side a large mass of vessels lying deeper on the surface of the tumour, and also to enucleate the lower part from the pelvis, peeling back the bladder, and enucleating the mass from the whole floor of the pelvis from the rectum and sigmoid flexure and left ureter on one side, and from the crecum and right ureter on the other, and well above the sacral promontory posteriorly, so that the raw surface, apart from the ovarian pedicles and uterine base secured in the serre-noud, was larger than that made in amputating at the hip-joint. Many large vessels were secured over this surface, and its edges were laced over with fine silk. Some venous oozing deep in the pelvis I failed altogether to stop, and I therefore placed a glass tube above the pedicle and at the bottom of the large cavity left by enucleation. The whole operation was performed antiseptically, the stump dressed with solid perchloride of iron, and the tube covered 